\title{
An Analysis of the Orientation and Emphasis of Intended Grade-10 Chemistry Curricula as Represented in Textbooks from Different Chinese Communities
}

\author{
Xiaoge Chen ${ }^{1 *}$, Mei-Hung Chiu ${ }^{2}$, Ingo Eilks ${ }^{1}$ \\ ${ }^{1}$ University of Bremen, Dept. of Biology and Chemistry, Institute for Science Education (IDN) - Chemistry Education, GERMANY \\ ${ }^{2}$ National Taiwan Normal University, Graduate Institute of Science Education, TAIWAN
}

Received 13 August 2018 • Revised 23 October 2018 • Accepted 16 November 2018

\begin{abstract}
This study presents an analysis of the representation of intended curricula in $10^{\text {th }}$ grade chemistry textbooks from different Chinese communities, namely from the People's Republic of China, Taiwan, and the Chinese minority in Malaysia. The study aims to identify the commonalities and differences among seven textbooks concerning the emphasis and orientation of the intended curriculum. It also looks at any indications of how student-oriented these curricula are in terms of the presentation of content and the suggested activities. The findings indicate that the Taiwanese textbooks have a high degree of contextualization and socio-scientific issues orientation, supported by rich and colorful illustrations as well as the integration of macro- and submicroscopic aspects of chemistry concepts. The textbook from Malaysia uses a quite traditional approach. It basically follows a structure-of-the-discipline orientation, using less contextualization and fewer illustrations. The textbooks from the People's Republic of China lie somewhere in between the textbooks from Taiwan and Malaysia. They offer some indications of student-oriented learning and have some extent of daily life and socio-scientific issues orientation.
\end{abstract}

Keywords: chemistry education, curriculum, textbooks

\section{INTRODUCTION}

Ever since the 1980s new goals and standards for secondary chemistry education have emerged in both Western and non-Western countries. In Western countries the new standards intended to refine the chemistry curriculum from the pure learning of chemistry facts and theories towards learning from everyday life perspectives and societal contexts (Eilks et al., 2013). A corresponding change towards science learning with a starting point in everyday life has also gradually been suggested as an important issue in several Asian regions like the People's Republic of China (Wang et al., 2016), Taiwan (Guo \& Chiu, 2016), Malaysia (Halim \& Meerah, 2016) and Korea (Choi \& Choi, 2016).

Textbooks are one of the main elements that influence what is taught in the classroom and how science is conveyed to students. A textbook can be seen as a go-between linking a domain of knowledge and the student (Devetak \& Vogrinc, 2013). It represents not only the intended curriculum, the content matter and contexts, but also the beliefs of its authors and their view of science and which aspects of science should be considered (Seligardi, 2006). The textbook presents the subject to the learners and suggests to teachers how the topics are to be taught (Shehab \& BouJaoude, 2015). It provides orientation in the curriculum and mirrors the emphasis behind it (Roseman et al., 2010). Textbooks serve as a handfast resource to support teachers with content, strategies and approaches for teaching and can also suggest how much support students need (Stein et al., 2001).

The most common research area involving science textbook analysis focuses on the construction of textbooks. It looks at the important ideas implemented in science textbooks (e.g. the nature of science), difficulties with textbooks, and the specific content structure used in textbooks. There are much fewer studies seeking to identify whether science textbooks are in line with modern theories of the curriculum. This is the case for science teaching

(C) 2019 by the authors; licensee Modestum Ltd., UK. This article is an open access article distributed under the terms and conditions of the Creative Commons Attribution License (http://creativecommons.org/licenses/by/4.0/).

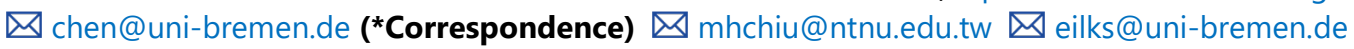




\section{Contribution of this paper to the literature}

- This paper provides an analysis of secondary chemistry textbooks from different Chinese communities, namely from the People's Republic of China, Taiwan, and the Chinese minority from Malaysia. The analysis focuses the orientation and emphasis of the intended secondary chemistry curriculum.

- The analysis revealed a large variety in the representation of the secondary chemistry curriculum in textbooks from different Chinese communities, with textbooks from Taiwan being mostly in line with modern, international chemistry curriculum theory. Chinese chemistry textbooks from Malaysia are very traditional with having textbooks from the People's Republic of China indicating progress towards issues of modern chemistry textbooks.

in general. It also holds true when comparing chemistry textbooks from different cultures or regions. Not much is known about why the intended curricula as represented in textbooks from different countries look so different to one another. This occurs even if the countries in question share the same culture, regional background, or level of economic development (Khaddoor et al., 2017). Khaddoor et al. (2017) examined chemistry textbooks from seven cross-regional Arab countries and suggested that the influence of tradition and educational policy might be the main factor that counts. However, this finding was based on comparing different Arab communities. To date no transnational science textbook comparisons for Chinese communities with a similar focus exist. Former studies on Chinese chemistry textbooks mainly focused on the content (Wang \& He, 2012), not so much on its representation.

This paper explores the characteristics of intended secondary chemistry curricula from different Chinese communities. It looks at $10^{\text {th }}$ grade chemistry textbooks from the People's Republic of China, Taiwan, and the Chinese minority living in Malaysia. The textbooks chosen are either officially approved by the government in question or authorized by the regional educational authorities. The questions addressed in this article are as follows:

1. What are the commonalities and differences in the intended chemistry curricula as represented by $10^{\text {th }}$ grade textbooks from different Chinese communities? What are the curriculum emphases and the orientations of the curriculum?

2. Are there any indications of modern, student-oriented chemistry curricula in terms of contextualization, societal issues orientation, and student-oriented activities?

\section{THEORETICAL FRAMEWORK}

The theoretical framework of this study was developed for a comparative analysis of secondary chemistry textbooks from different Arab countries by Khaddoor et al. (2017). Khaddoor et al. refer in their framework to the concepts of the curriculum emphases and curriculum orientations.

Curriculum emphasis was defined by Roberts (1982) as a set of hidden messages about the nature of science within a curriculum. He described curriculum emphasis as ' . . . a coherent set of messages about science (rather than within science). Such messages constitute objectives which go beyond learning the facts, principles, laws and theories of the subject matter itself - objectives which provide answers to the student question: Why am I learning this?' (Roberts, 1982, p. 245).

Based on an analysis of science curricula from about 100 years in Northern America, Roberts identified seven curriculum emphases: 1) everyday coping, 2) the structure of science, 3) science, technology and decisions, 4) scientific skill development, 5) offering correct explanations, 6) the self as explainer and 7) solid foundation. However, Roberts had already made clear that curriculum emphases cannot always be sharply distinguished from one another. They can be combined in certain curricula and they often change.

In 2005, Van Berkel took Roberts' ideas and transformed the original seven curriculum emphases into three more general ones. Van Berkel called them fundamental chemistry, knowledge development in chemistry, and chemistry, technology and society (see also Khaddoor et al., 2017; Van Driel et al., 2007):

- Fundamental Chemistry (FC) puts the learning of theoretical concepts and facts at the fore. The curriculum is based on the view that facts and concepts need to be learned first for later application and provide the best ground for understanding the natural world.

- Knowledge Development in Chemistry (KDC) is based on the idea that students should learn both how chemistry knowledge emerged and changed over time. It also attempts to show how it was influenced by the corresponding socio-historical context, thus making chemistry a culturally-determined system.

- Chemistry, Technology and Society (CTS) puts the interrelationship between science, technology and society at the center of the curriculum. Students should learn how to make decisions on societal issues that are connected to chemistry and technology and to learn how to effectively communicate about them. 
Eilks et al. (2013) recently described the idea of general orientations of the chemistry curriculum. Their work refers De Jong's (2006) idea that there are four basic domains from which the learning of chemistry can be approached. De Jong identified the personal, professional, professional-technological, and societal domains. His suggestion parallels what was recently identified as dimensions of relevance when it comes to science education: individual, societal and vocational relevance (see Stuckey et al., 2013).

Based on De Jong (2006), Eilks et al. (2013) identified six general orientations from which individual chemistry lessons might begin and from which curricula might be designed. In brief these are:

- Structure of the discipline orientation: The chemistry curriculum mirrors the inner structure of academic chemistry. The curriculum is designed for structured learning of scientific facts and theories. A corresponding school curriculum might look like a 'lighter' version of an academic general chemistry textbook.

- History of chemistry orientation: The chemistry curriculum is structured along episodes from the history of chemistry. The curriculum is designed to learn about the nature of chemistry and how chemistry knowledge emerged over time illustrated by references to the life of real chemists.

- Everyday life orientation: The chemistry curriculum is structured using everyday life topics and issues to provide meaningful contexts for learning chemistry concepts.

- Environmental orientation: The chemistry curriculum is structured by environmental issues and problems, including questions of environmental protection.

- Technology and industry orientation: The chemistry curriculum is structured by developments from chemical technology and industry. This might include the interplay of science and technology within society.

- Socio-scientific issues (SSI) orientation: The chemistry curriculum is structured by using controversial socio-scientific issues. It is suggested that students develop general skills to allow them to act as responsible citizens in society.

Khaddoor et al. (2017) suggest that all of the curriculum orientations described above can form a context of one type or another (see Gilbert, 2006) for the teaching and learning of chemistry. With reference to the theory of situated cognition (Greeno, 1998), they also state that contexts which should be meaningful to the student must be connected to the students' prior experiences. They argue that this is generally not true for both the structure of the discipline and history of chemistry orientations, at least for a majority of secondary school students. Contexts are believed to be more meaningful to students if taken from everyday life and environmental issues. It is also thought that corresponding contexts provide chances to illustrate the relevance of chemistry education to the individual learner (Childs et al., 2015). The same holds true for many technological and societal issues that offer links to demonstrate chemistry education's societal and vocational relevance (Hofstein \& Kesner, 2015; Sjöström et al., 2015).

If one wishes to connect curriculum emphases (as suggested by Van Berkel, 2005) with the idea of curriculum orientations (Eilks et al., 2013), the structure of the discipline orientation has been recommended as being closely related to Fundamental Chemistry. Using the history of chemistry orientation might be inspired by an emphasis on Knowledge Development in Chemistry. A focus on technology and industry might intend the same, if the focus is on referring to the development of certain technologies during history. Chemistry, Technology and Society can hardly be employed without incorporating topics and issues from the students' individual lives and society at large. It has been suggested that this approach is most prominent in curriculum orientations centering on everyday life, the environment and socio-scientific issues.

\section{BACKGROUND AND SAMPLE}

In the People's Republic of China, curricula and teaching are generally based on nationally unified material. In one of the recent curriculum reforms, upper secondary school chemistry curriculum standards were released in 2003 (Wang, 2010). This reform led to a push in studies about the learning of science in the People's Republic of China. Many related studies became available, e.g., on science teaching in general (Hu \& Wang, 2005), science teachers (Zhong, 2005), and scientific inquiry (Ding, 2010). Both the curriculum and textbooks became hot-button fields in science education in China (Wang et al., 2016).

This study focuses on three sets of upper secondary school chemistry textbooks from the People's Republic of China (with the exception of Shanghai), which were written according to the guidelines of the curriculum standards. They passed official review by the Ministry of Education ${ }^{1}$. These books were published by People's Education Press, Shandong Science and Technology Press and Jiangsu Education Press, respectively (Song, 2007a and b; Wang, 2007; Wang, 2014/2015). The three sets of textbooks are also known as the Renjiao Edition (later called $\mathrm{CN} 1)$, Luke Edition (CN2) and Sujiao Edition (CN3). For each set of textbooks, there are two books for compulsory 
courses and six books for elective courses. The two compulsory courses (Chemistry 1 and 2) represent a curriculum to be learned by all grade 10 students.

In 1985, the Shanghai College Enrollment Office was allowed to abstain from the Chinese National College Entrance Examination (NCEE) in order to try out an independent proposition. Its textbooks are edited and reviewed by the Shanghai Primary and Secondary School Curriculum Reform Committee and Shanghai Primary and Secondary School Textbook Review Committee, respectively. In 1998 Shanghai started the second cycle of curriculum reform (Sun et al., 2016) and corresponding textbooks were printed. The Shangke Edition (CN4) (Yao, 2007a and b) published by Shanghai Scientific and Technical Publisher was recommended by the Shanghai municipal education committee. A special focus on Shanghai is justified here because Shanghai is one of the most industrialized areas in the People's Republic of China.

Ever since the 1950s, basic education in Taiwan has been described as a development from transformation to innovation (Liu, 2010). Taiwan declared 1954 as the Year of Scientific Development (Liu \& Chiu, 2012). Science education as an emphasis was starting to gain more attention from the government than in the past. Over the past decades, science textbooks in Taiwan were compiled by the National Translation and Compilation Center (NTCC). In 1994 rapid developments and changing societal needs led to an influential educational reform. This reform emphasized the eliciting of constructive learning and the cultivation of students as $21^{\text {st }}$ century citizens was promulgated for grades 1-9. Science education was transformed from an elite education of the few to science for all. A major feature of the reform was the end of the NTCC monopoly on textbook compilation and publishing. Private publishers are now allowed to draft and publish textbooks for school use. Since 2001, the focus has shifted towards the needs of varying students groups. School-based curricula that are more flexible and creative were also allowed (Xiong \& Chen, 2001). A new curriculum guideline (sometimes also called standards or syllabi) was launched in 2018 and will be fully implemented by 2020. The new guidelines for science curricula emphasize the cultivation of core scientific literacy. This includes scientific core concepts, inquiry-based practice, and a motivation towards science and the nature of science. For this study, we chose two sets of widely-used chemistry textbooks for $10^{\text {th }}$ grade students in Taiwan, published by Lungteng Cultural (Huang, 2010) and Nan-I Book Enterprise (Yeh, 2010). Hereafter we will refer to them as the Lungteng Edition (TW1) and Nan-I Edition (TW2), respectively. ${ }^{2}$ Both textbooks were based on the Compulsory Subject Basic Chemistry Curriculum Syllabus for Senior Secondary Schools, which was released by the Ministry of Education of Taiwan (2006).

Malaysia is a country with a Chinese minority which makes up roughly $25 \%$ of the whole population. The Chinese minority sector in Malaysia operates its own educational system and schools, teaching students mainly in Chinese (Karpudewan \& Chua, 2016). Chinese education in Malaysia began in 1819. In 1954, the United Chinese School Committees' Association of Malaysia (UCSCA or Dong Zong) was established to defend and develop Chinese language education and aims to achieve the sustainable development of Chinese education. It works with the United Chinese School Teachers' Association of Malaysia (UCSTA or Jiao Zong) to uphold the ethnic rights of the Chinese minority. The two associations are known by the acronym of Dong Jiao Zong (Dong Zong and Jiao Zong) (Dong Zong, 2017). Independent schools are operated by Dong Jiao Zong instead of by the Ministry of Education in Malaysia. Any rules and regulations in these schools are different from those in the governmental schools. Students who go to Malaysian independent Chinese secondary school have an additional academic year of upper secondary school, similar to the secondary school system in the People's Republic of China and Taiwan. The Malaysian high school chemistry book (Upper Secondary School Chemistry) is edited by the Malaysia Independent Chinese Secondary School Working Committee (MICSS) and is based on the chemistry syllabus for secondary schools. There are three volumes of upper secondary school chemistry textbooks for students from grade 10 to grade 12. In this study, the Upper Secondary School Chemistry Textbook for grade 10 students (MICSS, 1996; later called MY1) was analyzed. ${ }^{3}$

Altogether, the sample for the current study consists of seven textbooks for the first year of upper secondary education (grade 10) in different Chinese communities. There are three sets of textbooks (Renjiao Edition, Luke Edition and Sujiao Edition, CN1-CN3) that are widely used in many provinces in the People's Republic of China. One other textbook (Shangke Edition, CN4) is mainly used in Shanghai. Two textbooks stem from Taiwan (Lungteng Edition and Nan I Edition, TW1-TW2) and one textbook is from Malaysia (MY1). All the textbooks are compiled either in simplified Chinese (CN1-4, MY1) or traditional Chinese (TW1-2). More information is available in Appendix 1.

\section{METHOD}

The textbooks were qualitatively and interpretatively analyzed in a cyclical approach as described by Khaddoor et al. (2017). All data were analyzed in an iterative, back-and-forth process (Teddlie \& Tashakkori, 2009). A first cycle was carried out for technical aspects of the textbooks as inspired by Devetak and Vogrinc (2013). The first cycle of analysis focused on structural elements found in the textbooks, including the number of chapters, pages, pictures, etc. (Table 1). 
Table 1. Criteria for the first cycle of analysis (adapted from Devetak \& Vogrinc, 2013)

\begin{tabular}{|c|c|c|}
\hline General criteria & Subcategory & Description \\
\hline General structure & $\begin{array}{l}\text { - Number of pages } \\
\text { - Chapters } \\
\text { - English words } \\
\text { - Exercises }\end{array}$ & $\begin{array}{l}\text { The structure of the textbook that is the focus in the analysis. Each } \\
\text { element of the structure is analysed and categorized. }\end{array}$ \\
\hline Textual material & $\begin{array}{l}\text { - Learning goals } \\
\text { - Instructions for practical work } \\
\text { - Appearance of modern issues }\end{array}$ & $\begin{array}{l}\text { This analysis identifies the frequency and placement of the subcategories. } \\
\text { Is descriptive/narrative information about key facts, concepts, principles } \\
\text { and laws, etc. more subject or scientific field driven? Does the text present, } \\
\text { discuss, identify or reflect upon scientific knowledge on a harmonized } \\
\text { level? }\end{array}$ \\
\hline $\begin{array}{l}\text { Numbers of } \\
\text { visual } \\
\text { representations }\end{array}$ & $\begin{array}{l}\text { - Everyday life images } \\
\text { - Sub-microscopic pictures } \\
\text { - Pictures with human beings }\end{array}$ & $\begin{array}{l}\text { This step looks for pictures from everyday life, about scientific models and } \\
\text { sub-microscopic illustrations, or pictures with human beings. }\end{array}$ \\
\hline
\end{tabular}

A second cycle analysed the textbooks using an inductive approach, it was nevertheless inspired by the issues described in Khaddoor et al. (2017). The final categories include the representation of content, use of visual representations, suggestions for practical work and activities, issues of tasks and assessment, appearance of modern issues in chemistry, the curriculum emphases, and the orientation of the curriculum. Each category was checked for appearance of any potential sub-categories given in Table 2. All the main characteristics from Table 2 were then interpretatively rated to which degree the corresponding feature and its sub-categories are present in the book and which role they play using a four-step scale as given in Table 3.

Table 2. Categories for developing the characterization of the textbooks adapted from Khaddoor et al. (2017)

\begin{tabular}{|c|c|}
\hline Category & Subcategory \\
\hline Content representation & $\begin{array}{l}\text { - Chapters contain introductions and summaries } \\
\text { - Chapters provide context-based overviews and describe prerequisite skills } \\
\text { - Theories, facts and principles are embedded in meaningful contexts } \\
\text { - Metaphors, analogies and models are used to support content } \\
\text { - Texts are referred to non-textual representations } \\
\text { - Interdisciplinary references are integrated } \\
\text { - Vocational orientation is provided }\end{array}$ \\
\hline Visual representation & $\begin{array}{l}\text { - Visual aids and colourful pictures are used for illustration } \\
\text { - Images/visual elements support text/explanation } \\
\text { - Visualizations support sub-microscopic level understanding }\end{array}$ \\
\hline $\begin{array}{l}\text { Practical work and } \\
\text { activities }\end{array}$ & $\begin{array}{l}\text { - Practical activities are suggested } \\
\text { - Experiments are suggested to resonate with students' interests } \\
\text { - Inquiry-based experiments are suggested } \\
\text { - Online learning is suggested }\end{array}$ \\
\hline Tasks and assessment & $\begin{array}{l}\text { - Real world applications are used in problem-solving tasks } \\
\text { - Assessment uses multilevel type questions } \\
\text { - English learning is integrated with science learning }\end{array}$ \\
\hline Modern issues in chemistry & $\begin{array}{l}\text { - Environmental and sustainability issues } \\
\text { - Modern technologies, e.g. nano-chemistry }\end{array}$ \\
\hline Curriculum emphasis & $\begin{array}{l}\text { - Fundamental Chemistry } \\
\text { - Knowledge Development in Chemistry } \\
\text { - Chemistry, Technology, Society }\end{array}$ \\
\hline Curriculum orientation & $\begin{array}{l}\text { - Structure of the discipline orientation } \\
\text { - History of science orientation } \\
\text { - Everyday life orientation } \\
\text { - Environmental orientation } \\
\text { - Industry and technology orientation } \\
\text { - Socio-scientific issues orientation } \\
\end{array}$ \\
\hline
\end{tabular}


Table 3. Pattern to interpret the presence and role of certain features in the textbooks

\begin{tabular}{ll}
\hline Description & Example \\
$\begin{array}{l}\text { The corresponding feature is present throughout the book } \\
\text { and plays a central role in the appearance and character of the } \\
\text { book. }\end{array}$ & $\begin{array}{l}\text { Contexts or colorful illustrations are used throughout the } \\
\text { whole book to approach content learning. The chapters start } \\
\text { with contexts and illustrations leading to chemistry content. }\end{array}$ \\
$\begin{array}{l}\text { The corresponding feature is present throughout the book, } \\
\text { but it does not play a central role in the appearance and } \\
\text { character of the book. }\end{array}$ & $\begin{array}{l}\text { Contexts or colorful illustrations are regularly used in the book } \\
\text { to support and illustrate content learning. But the learning } \\
\text { does not really begin with the contexts and illustrations. }\end{array}$ \\
$\begin{array}{l}\text { The corresponding feature is present in the book, but only in } \\
\text { certain places and plays a minor role in the appearance and } \\
\text { character of the book. }\end{array}$ & $\begin{array}{l}\text { Contexts or colorful illustrations are used in the book to } \\
\text { support learning, But the contexts and illustrations are only } \\
\text { used here and there and not systematically. }\end{array}$ \\
\hline $\begin{array}{l}\text { The corresponding feature is absent or almost completely } \\
\text { absent in the book. }\end{array}$ & $\begin{array}{l}\text { Contexts or colorful illustrations are very rarely (or never) used } \\
\text { in the book to support learning. }\end{array}$ \\
\hline
\end{tabular}

A final round of analysis based on a memo-approach. The memo-approach was done by writing a memo, a short characteristic text, of each of the textbooks that then was discussed in the research group to whether it sufficiently characterizes the textbooks in terms of the first two cycles of the analysis. This step of analysis captured links, looked for relationships, asked questions of the collective data, and identified the main concerns for each of the textbooks for later comparison. This analysis aimed to give a general description of the textbooks' characteristics in terms of content representation, suggested activity, modern topics, curriculum emphases, curriculum orientation, and any overall indicators for modern, student-centred science education. The memos were validated in a communicative process among the authors. Each memo was checked backward and forward across the data from the process of analysis in order to provide interpretation, express the main position and keep track of the train of logic. All the analyses were done by the first author under supervision of the third author and checked and discussed among all authors for final interpretations.

\section{FINDINGS}

Our findings suggest that a wide variety of characteristics exists among the textbooks concerning how the intended curriculum is presented to the teacher and learner. However, there are larger differences between the textbooks from different Chinese communities than there are within them. This holds true for the People's Republic of China, Taiwan and the Chinese minority in Malaysia. The main topics in the different textbooks can be found in Appendix 2. Selected characteristics from the first round of analysis are given in Appendix 3. Table 4 provides a comparison of the different textbooks with reference to certain characteristics that emerged during the second cycle of analysis. The textbooks were interpreted to whether certain features are used in a high, medium, or low way, or are almost absent with respect to the characterization of Table 3. If certain characteristics appeared throughout the textbook, we coded this as "high". If the corresponding characteristics is very limited or even absent in the textbook, we coded it as "low". If the characteristic is used discontinuously this was coded as "medium". Table 5 provides an overview about the dominant curriculum emphasis and the prevalent curriculum orientations operated in each of the textbooks.

Table 4. Rating of certain characteristics of the textbooks

\begin{tabular}{cccccc} 
Textbook & $\begin{array}{c}\text { Meaningful textual } \\
\text { contextualisation } \\
\text { of content }\end{array}$ & $\begin{array}{c}\text { Meaningful and rich } \\
\text { use of visual } \\
\text { representations }\end{array}$ & $\begin{array}{c}\text { Suggestions for } \\
\text { practical work }\end{array}$ & $\begin{array}{c}\text { Use of tasks and } \\
\text { assessment }\end{array}$ & $\begin{array}{c}\text { Appearance of } \\
\text { modern issues }\end{array}$ \\
\hline CN1 & medium & medium & high & medium & medium \\
\hline CN2 & medium & medium & high & medium & medium \\
\hline CN3 & medium & medium & medium & medium & medium \\
\hline CN4 & medium & medium & medium & medium & low \\
\hline TW1 & high & high & low & high & high \\
\hline TW2 & high & high & medium & high & medium \\
\hline MY1 & low & low & low & medium & low \\
\hline
\end{tabular}

Table 4 indicates the contextualization of content and the rich use of visual representation in Taiwanese textbooks, while contextualization in the Malaysian textbook is quite limited. Textbooks from China lie in between. The structure of discipline curriculum orientation in the Malaysian textbook is dominant. This orientation is lower in textbooks from the Peoples Republic of China. Also in Taiwan it is not very dominate while the chemistry, technology and society emphasis is considered being more important (Table 5). 
Table 5. Prevalent curriculum emphasis and used curriculum orientations

\begin{tabular}{|c|c|c|}
\hline Textbook & Main curriculum emphasis & Use of orientations of the curriculum operated in the book \\
\hline CN1 & ( & $\begin{array}{ll}\text { - } & \text { structure of the discipline (medium) } \\
\text { - } & \text { everyday life (medium) } \\
\text { - } & \text { history of chemistry (low) } \\
\text { - SSI (low) } \\
\text { - industry and technology (low) } \\
\text { - environmental (low) } \\
\end{array}$ \\
\hline $\mathrm{CN} 2$ & FC & $\begin{array}{l}\text { - } \text { everyday life (high) } \\
\text { - structure of the discipline (medium) } \\
\text { - industry and technology (medium) } \\
\text { - history of chemistry (low) } \\
\text { - SSI (low) } \\
\text { - environmental (low) }\end{array}$ \\
\hline CN3 & FC & $\begin{array}{l}\text { - SSI (high) } \\
\text { - } \quad \text { structure of the discipline (medium) } \\
\text { - } \quad \text { industry and technology (medium) } \\
\text { - history of chemistry (low) } \\
\text { - } \quad \text { environmental (low) }\end{array}$ \\
\hline $\mathrm{CN} 4$ & FC & $\begin{array}{l}\text { - } \text { structure of the discipline (high) } \\
\text { - } \text { history of chemistry (high) } \\
\text { - everyday life (low) } \\
\text { - } \text { industry and technology (low) } \\
\text { - environmental (low) } \\
\end{array}$ \\
\hline TW1 & CTS & $\begin{array}{l}\text { - } \text { everyday life (high) } \\
\text { - history of chemistry (high) } \\
\text { - SSI (high) } \\
\text { - industry and technology (medium) } \\
\text { - } \text { structure of the discipline (low) } \\
\text { - environmental (low) }\end{array}$ \\
\hline TW2 & CTS & $\begin{array}{l}\text { - } \text { everyday life (high) } \\
\text { - } \text { history of chemistry (high) } \\
\text { - SSI (high) } \\
\text { - } \text { environmental (medium) } \\
\text { - industry and technology (low) } \\
\text { - structure of the discipline (low) }\end{array}$ \\
\hline MY1 & FC & $\begin{array}{l}\text { - } \text { structure of the discipline (high) } \\
\text { - } \text { history of chemistry (low) } \\
\text { - everyday life (low) } \\
\text { - } \text { environmental (low) }\end{array}$ \\
\hline
\end{tabular}

\section{People's Republic of China}

The textbooks from the People's Republic of China have many similarities in their intended curriculum structure, content framework, and visual representation. Charts, tables, diagrams, pictures are provided to support learning from the texts. Submicroscopic models aid learning about theories and laws in certain places, but their use is limited.

Indications of context-based learning can be found in all the textbooks CN1-4, but they generally do not aid learning as a starting point. The Luke (CN2) textbook offers more everyday life pictures compared to the other three textbooks and practical activities related to everyday life are suggested by this book in certain places. Examples include looking at the labels on food, condiments, household cleaners, pill bottles and cosmetics and in listing the names of substances which contain chlorine, bromine or iodine. Everyday life pictures are linked to theoretical learning. For example, the use of sodium hypochlorite disinfectant is taken as the context for approaching chlorine containing compounds. Environmental issues are quite limited in these four textbooks. Green chemistry and nanotechnology are briefly mentioned in certain places.

In terms of content representation, theories, concepts, facts, principles and laws are embedded in contexts at specific points. Interdisciplinary approaches can be found in the Renjiao/Luke/Sujiao (CN1/CN2/CN3) textbooks, mainly dealing with chemistry-biology, chemistry-pharmacy, except for the Shangke textbook (CN4). The Shangke textbook focuses more on chemistry-English interdisciplinary learning. The textbook applies English tasks 
consistently throughout the book. For example, a short essay related to acid rain is provided for students' reading comprehension skills and an essay related to chlorine asks students to write down related chemical equations in combination with their English reading comprehension and chemistry knowledge. All of the other textbooks apply English terms in differing degrees, most of them, however, involve English learning only at the level of providing essential key words.

Pictures of human beings are used in each textbook, with the Shangke textbook (CN4) having the lowest number of representations. A Chinese chemical industrialist, Wu Yunchu, and a Chinese revolutionary, Fang Zhimin, are mentioned by this book, but no Chinese scientists are mentioned. The Sujiao textbook (CN3) presents aspects of the history of science in connection with chemical theory development using examples like the chronological progression of models of atomic structure, the construction of the periodic table, etc. One aspect refers to the Hou's process for soda production, which was developed by the Chinese chemist, Hou Debang. Other examples include the synthesis of aspirin and the application of penicillin in the Second World War. Historical science is employed in the Shangke textbook (CN4), which discusses the discovery of batteries, covers the story of human beings recognizing the function of catalysts, and tells individual scientists' stories with pictures.

Experiments in all the four textbooks are clearly described with specific reagents and detailed instructions. Charts with blank fields are provided for students to write down experimental records. Inquiry-based learning can be found in certain places, but is limited in scope. Internet searches are mainly suggested as online learning exercises to find more information on topics like the elements, health issues, acid rain, the periodic table of the elements, etc. Diversified vocations are mentioned widely by the Luke textbook (CN2), which assigns equal emphasis in terms of vocational status. Common vocations described included: researcher, chemist, doctor, fireman, athlete, engineer, technician, teacher, and policeman.

Basically, all the textbooks from the People's Republic of China focus on fundamental knowledge. Theories, concepts, facts, principles and laws are connected to meaningful contexts, but the contexts are generally not discussed on their own right. Indications for student-active learning can be found, e.g. industry visits (CN4), essay writing, brainstorming, role play tasks (CN1), hands-on creation work (CN2), but are quite limited in extent. Some topics are also connected to socio-scientific issues, for example, exhausts from cars or the context that coal burning in power plants can lead to nitrogen oxides and sulfur dioxide that can cause acid rain (CN4). In addition, one chapter introduces issues of chemistry in connection to human civilization and the use of new energy supplies and sustainable development (CN3), but this does not play a central role in the intended curriculum. The representation of technology and society issues is also linked to theoretical learning at certain places.

The differences between CN1-3 and the textbook from Shanghai (CN4) lie mainly in the more intense use of contextualization provided at the beginning of each chapter, more use of English language tasks, and more references to the historical development of chemistry in CN4. Nevertheless, the Shangke (CN4) textbook maintains a content-based rather than context-based approach and thus is not substantially different from the CN1-3 textbooks.

\section{Taiwan}

In terms of the presentation of the intended curriculum, both Taiwanese textbooks provide thorough contextual introductions and illustrations. Every chapter is based on textual and pictorial contextualization. It is notable that both Taiwanese textbooks include more visual representations than the textbooks from the other Chinese communities. The modes of representation include links between the macro- and submicroscopic levels. They also use macro-symbolic and macro-submicro-symbolic representations. These linkages allow learners to visualize and construct unobservable chemical knowledge meaningfully. This unique adoption of representations is found throughout the textbooks, and the representations are also aligned with the three important representational levels of chemistry, namely macroscopic, submicroscopic, and symbolic representations (Johnstone, 1993, 2000; Talanquer, 2011).

Theories, concepts, facts, principles and laws are embedded in consistent and meaningful contexts in the Taiwanese textbooks. Contextualized metaphors and analogies are arranged to support the learning of basic concepts. Images of submicroscopic models are integrated as scaffolding tools to enhance visualization and understanding of the chemical knowledge (such as balancing chemical equations). For example, the process of making a cup of tea and the different character of moorstone and stainless steel (TW1) are described by the text. Pictures illustrate the production and molecular representations of the processes to promote students' understanding of the classification of matter and the difference between homogeneous and heterogeneous mixtures of substances. Similar contextualized examples (such as hand warmers) can be found throughout the book. This can be viewed as an indicator of context-based learning that relates to students' lives. Everyday life applications appear in the Taiwanese textbooks in each chapter. Gender balance is also taken into consideration for human character illustrations. Socio-scientific issues such as the alleged energy crisis and renewable energy exploitation 
are also included. However, the socio-scientific issues focus the scientific content and do not provide any socioeconomic reflection. Genetic engineering is mentioned in TW1. Green chemistry is also discussed in one of the Taiwanese textbooks (TW2).

The design of the Lungteng Edition (TW1) offers a concept map at the very beginning of the textbook and provides an overview of the key concepts to be learned in each chapter. At the end of each chapter, in addition to a summary, the Nan-I Edition (TW2) provides an extra concept tree to summarize key concepts/laws/theories; it also explicitly highlights learning objectives in terms of concepts and competence with different levels of epistemic understanding, such as knowing, understanding, describing, explaining, etc. Examples are (1) to know the difference between pure substance and mixture, (2) to understand the meaning of valence electron and valence shell, (3) to describe the 18 groups in the periodic table, and (4) to explain the properties of metal elements. There is also limited integration of interdisciplinary references.

Both Taiwanese textbooks provide also a glossary of chemical terms with their English equivalents. The purpose of the English translation is to prepare students for university level coursework, in which English terminology is often used. The history of science is described chronologically, with TW1 focusing basically on the knowledge development in science and TW2 targeting the scientists and their contributions to the development of science.

The two textbooks seem to place less emphasis on student participation in experiments, except for a few demonstrations like chromatography in TW2. Experiments are mostly presented by colorful images without much description of the procedures. No observational details for the experiments are mentioned. Practical activities like making a weather bottle or building a hydrogen oxygen fuel battery car are mentioned as supplementary resources but include few instructions. This lack of hands-on activities in the textbooks was not due to an ignorance about the importance of experiments on Taiwan's part. On the contrary, experiments are considered to be a central pillar of scientific disciplines. A separate book for laboratory activities is suggested to be used by the students.

Although the Taiwanese textbooks cover key concepts in chemistry, the depth of the content does not match that found in the Chinese textbooks. The topics provided by both of the two Taiwanese textbooks for grade 10 (Appendix 2) is nearly half the amount of the content in the textbooks from Mainland China (CN1-4). When compared to the Malaysian textbooks, where 14 chapters appeared in grade 10, the topics in the Taiwanese textbook are not dealt with in a similar depth. This is not to say that Taiwanese textbooks have "easier" content, since in the Taiwanese curriculum the deeper content found in the Chinese textbooks were moved to Grades 11 and 12 as electives for science majors. The focus of $10^{\text {th }}$ grade science in Taiwan is not stuffing as much information into the students as possible. As the characteristic of the textbooks showed in Table 4 and the curriculum emphasis and orientation demonstrated by Table 5, it can be seen that contextualization in the Taiwanese textbooks is high, while the textbooks from Mainland China are to be considered as medium contextualized. Rather it is to strengthen the foundations upon which students can build, should they choose to become science majors the following year. Further data shows that the $10^{\text {th }}$ grade Taiwanese textbooks aim at providing basic chemical principles and applications rather than focusing practical skills development or using demonstrations (Appendix 3). Consequently, the textbooks from Taiwan focus more on conceptual understanding as compared to the textbooks from China, which focus more on algorithmic problem solving.

\section{Malaysia}

The textbook from Malaysia is quite traditional and focuses mainly on fundamental chemistry learning. Images/visual elements are provided to help text comprehension, but occur mostly in gray-scale. Almost no colorful, high resolution illustrations can be found. Theoretical perspectives are emphasized much more than everyday life events. Students' present and anticipated interests are insufficiently embodied.

Five out of the fourteen chapters begin chemistry learning without using any meaningful context as an introduction. The rest of the chapters are supported by simplified contextualization, which at least tries to connect learning of chemistry with everyday life applications to a limited extent. Metaphors, analogies and models can be found, but only in limited places. At several points the curriculum refers to technological and environmental issues such as hydrogen energy, solar energy, embryo cryogenics, fiber-optic cables, and acid rain. Essential academic English terms are provided throughout the textbook. Both men and women are shown in pictures in the textbook. The history of science can be found in references to alchemy, the progression of models of atomic structure, and the milestones of modern chemical theories.

Practical activities and online learning are less-well represented. Exercises given by the Malaysian textbook focus almost completely on basic theories, facts and laws, rather than on real world applications and problemsolving activities. Inquiry-based learning is absent. Some experimental descriptions are difficult to image because they are only presented in black-and-white or gray-scale pictures. Summaries at the end of each chapter are provided with simplified overviews. Overall, the textbook from Malaysia presents chemistry in the least contextualized and illustrated manner of all seven textbooks in the sample. 


\section{DISCUSSION AND CONCLUSION}

As mentioned before, there are larger differences between the textbooks from different Chinese communities than within them. This is especially the case in terms of the Taiwanese books. Both the two Taiwanese textbooks almost share the same amount of page number (see Appendix 3) and very similar topics (see Appendix 2). This is also the case for the CN1-3 textbooks (see Appendix 2 \& 3), but not for the case of CN4. The reason might be that the books in this study are each written according to different official curriculum standards released by corresponding Ministries of Education. The textbook editing community generally consists of education specialists, teachers and researchers, while the editors (mostly education specialists) are in charge of decision-making, designing, organizing and implanting of the textbook editing (Sun et al., 2016).

Our findings indicate a wide range of different curriculum emphases and orientations in the seven selected textbooks, as it was also described for a set of Arab countries by Khaddoor et al. (2017). Some of the intended curricula can be considered to be driven by applications of chemistry, relevant issues, and processes as described by Holman (1987). This is the case for the textbooks from Taiwan and to a certain extent, by several textbooks from the People's Republic of China. There are, however, indications that the textbooks from the People's Republic of China could be better align the learning of chemistry with everyday life contexts and societal views on the applications of chemistry as it is suggested in reform for science education in the People's Republic of China (Wang et al., 2016). The textbook from Malaysia is the most traditional of the group. It operates mainly as a vehicle conveying a fundamental chemistry emphasis and a structure-of-the-discipline orientation of the curriculum as it was prevalent in Western science education up to the 1970s (Eilks et al., 2013) and still is in many other countries of the world until today (Khaddoor et al., 2017). It makes very little use of meaningful contexts from everyday life, technology, the environment, or society and thus is not in line with modern trends for chemistry curricula (Eilks et al., 2013).

In this sample, the textbooks from Taiwan seem to best fit what modern research prescribes for chemistry curricula and their representations, namely student-active learning embedded in meaningful contexts (Eilks et al., 2013) with rich and helpful illustrations (Devetak \& Vogrinc, 2013). Both Taiwanese textbooks try to embed chemistry into the details of students' lives in order to make it more relevant or at least to promote the perception of relevance as e.g. discussed in Childs, Hayes and O'Dwyer (2015). In addition, linkage between phenomena at the macroscopic, microscopic, and symbolic levels are effectively used in order to promote a better understanding of chemistry (Johnstone, 1991). Basically, these representations support a chemistry-technology-society curriculum emphasis and orientation which is suggested to go beyond simple contextualization by everyday life orientation (Hofstein, Eilks \& Bybee, 2011). Based upon PISA results, students from Taiwan and some other Asian countries and regions outperformed other participating countries. But they also showed lower interest and motivation in learning science. A context-based approach in textbooks might be a solution to move students from rote memorization to active application when learning (King, 2012). Textbooks from the People's Republic of China are more limited in this respect compared to the textbooks from Taiwan. Yet the People's Republic of China has recently started curriculum reform towards a more context-based education (Huang, 2004). Indications of more contextualization in textbooks seem to emerge from this movement assumed that older textbooks were more traditional in this respect as they were in many countries of the world (Eilks et al., 2013). The textbooks from the People's Republic of China today show indications of beginning focus on context-based and societal-oriented chemistry education, which is now starting to be implemented. The same cannot yet be said for the Chinese minority textbooks from Malaysia.

Taiwan has been closely following the research and development of science curricula started in Western countries since the 1970s. Taiwanese science educators have also been actively participating in and contributing to the international science education community since then (Chiu, 2016). This may have influenced the Taiwanese curriculum and the style of textbooks designed to a large extent. The People's Republic of China started this process later. In the last few decades, however, science education researchers from the People's Republic of China have also made great efforts and shown progress in the internationalization of science education research (e.g. Liu, Liang \& Liu, 2012). Researchers from the People's Republic of China started reflecting both their own traditions in science education as well as how it relates to Western view on the science curriculum with in the international science education community (Wang, Wang, Zhan, Lang \& Mayer, 1996). The textbooks from the People's Republic of China seem to integrate international trends into the chemistry curriculum, such as a stronger focus on contextbased and societal-oriented chemistry education. It appears, however, that the corresponding changes have only started to be implemented. Time will tell. This process is one that Chinese chemistry education in Malaysia might consider to imitate. 


\section{LIMITATIONS}

This study has tried to provide insight into the large variety of Chinese chemistry curricula found in textbooks from several Chinese communities. It did not analyze all available textbooks. Instead it focused only on textbooks from compulsory modules of $10^{\text {th }}$ grade chemistry education and analyzed only selected aspects of the textbooks. In its current form, our study can make no predictions about how and in what manner the textbooks are being used by teachers. Nor can it address the extent to which teachers use additional resources in their chemistry classes. This would be an interesting starting point for further research efforts.

\section{NOTES}

${ }^{1}$ The Ministry of Education of the People's Republic of China guides national education reform, development, language policy as well as international communicating and operating. The newest upper secondary school chemistry curriculum standard was released in the end of 2017 and suggested to promote in 2018 fall. The samples in this study are based on the upper secondary school chemistry curriculum standards released in 2003.

2 By the time we conducted the study, TW2 textbook is still used in Taiwan, from 2017 to 2018, a new version is edited and updated and go into market in August 2018.

${ }^{3}$ By the time we conducted the study, the Upper Secondary School Chemistry Textbook is still used in Malaysia independent Chinese secondary school, from 2018, a new version is implied.

\section{ACKNOWLEDGEMENTS}

This research is supported by a PhD grant from the China Scholarship Council (CSC). We would also like to thank Professor Mageswary Karpudewan (Malaysia) for cooperating with us on this project.

\section{REFERENCES}

Childs, P. E., Hayes, S. M., \& O'Dwyer, A. (2015). Chemistry and everyday life: relating secondary school chemistry to the current and future Lives of students. In I. Eilks \& A. Hofstein (Eds.), Relevant chemistry education (pp. 33-54). Rotterdam: Sense. https://doi.org/10.1007/978-94-6300-175-5_3

Chiu, M.-H. (Ed.). (2016). Science education research and practices in Taiwan. Dordrecht: Springer. https:/ / doi.org/10. 1007/978-981-287-472-6

Choi, B.-S., \& Choi, A. (2016). Overview of science education research and practice in Korea. In M.-H. Chiu (Ed.), Science education research and practice in Asia (pp. 245-273). Dordrecht: Springer. https://doi.org/10.1007/ 978-981-10-0847-4_14

De Jong, O. (2006). Making chemistry meaningful: conditions for successful context-based teaching. Educación Química, 17, 215-226. https:/ / doi.org/10.22201/fq.18708404e.2006.4e.66010

Devetak, I., \& Vogrinc, J. (2013). The criteria for evaluating the quality of the science textbooks. In M. S. Khine (Ed.), Critical analysis of science textbooks (pp. 3-15). Dordrecht: Springer. https:/ / doi.org/10.1007/978-94-007-41683_1

Ding, B. P. (2010). On the typologies and essential characteristics of inquiry-oriented science teaching. Educational Research, 2010(10), 81-85.

Dong Zong (2017). The background of Dong Zong's establishment. Retrieved on June 30, 2018, from http:/ / www.dongzong.my/eindex.php

Eilks, I., Rauch, F., Ralle, B., \& Hofstein, A. (2013). How to allocate the chemistry curriculum between science and society. In I. Eilks \& A. Hofstein (Eds.), Teaching chemistry-A studybook (pp. 1-36). Rotterdam: Sense. https://doi.org/10.1007/978-94-6209-140-5_1

Gilbert, J. K. (2006). On the nature of context in chemical education. International Journal of Science Education, 28(9), 957-976. https:/ / doi.org/10.1080/09500690600702470

Greeno, J. G. (1998). The situativity of knowing, learning, and research. American Psychologist, 53(1), 5-26. https://doi.org/10.1037/0003-066X.53.1.5

Guo, C.-J., \& Chiu, M.-H. (2016). Opportunities and challenges for science education in Asia: Perspectives based on the Taiwan experience. In M.-H. Chiu (Ed.), Science education research and practice in Asia (pp. 175-196). Dordrecht: Springer. https://doi.org/10.1007/978-981-10-0847-4_10 
Halim, L., \& Meerah, T. S. M. (2016). Science education research and practice in Malaysia. In M.-H. Chiu (Ed.), Science education research and practice in Asia (pp. 71-93). Dordrecht: Springer. https:/ / doi.org/10.1007/978981-10-0847-4_5

Hofstein, A., Eilks, I., \& Bybee, R. (2011). Societal issues and their importance for contemporary science education: a pedagogical justification and the state of the art in Israel, Germany and the USA. International Journal of Science and Mathematics Education, 9(6), 1459-1483. https:/ / doi.org/10.1007/s10763-010-9273-9

Hofstein, A., \& Kesner, M. (2015). Learning from and about Industry for Relevant Chemistry Education. In I. Eilks \& A. Hofstein (Eds.), Relevant chemistry education (pp. 285-299). Rotterdam: Sense. https:/ / doi.org/10.1007/978-94-6300-175-5_15

Holman, J. (1987). Resources or courses? Contrasting approaches to the introduction of industry and technology to the secondary curriculum. School Science Review, 68(244), 432-438.

Huang, D. S. (2010). Basic Chemistry 1 (1st ed.). Taiwan: LungTeng Culture Co., Ltd.

Huang, F. Q. (2004). Curriculum reform in contemporary China: seven goals and six strategies. Journal of Curriculum Studies, 36(1), 101-115. https:/ / doi.org/10.1080/002202703200004742000174126

Hu, J. H., \& Wang, L. (2005). Scientific teaching exploration - an inquiry-based constructive teaching. Education Science Research, 2005(4), 35-37.

Johnstone, A. H. (1991). Why is science difficult to learn? Things are seldom what they seem. Journal of Computer Assisted Learning, 7(2), 75-83. https:/ / doi.org/10.1111/j.1365-2729.1991.tb00230.x

Johnstone, A. H. (1993). The development of chemistry teaching: A changing response to changing domain. Journal of Chemical Education, 70(9), 701-705. https:/ / doi.org/10.1021/ed070p701

Johnstone, A. H. (2000). Teaching of chemistry-logical or psychological? Chemistry Education Research and Practice in Europe, 1(1), 9-15. https:/ / doi.org/10.1039/A9RP90001B

Karpudewan, M., \& Chua, K. E. (2016). Cultural background and the science laboratory learning environment: The Malaysian lower secondary students' perspective. In I. Eilks, S. Markic \& B. Ralle (Eds.), Science education research and practical work (pp. 93-104). Aachen: Shaker.

Khaddoor, R., Al-Amoush, S., \& Eilks, I. (2017). A comparative analysis of the intended curriculum and its presentation in 10th grade chemistry textbooks from seven Arabic countries. Chemistry Education Research and Practice, 18, 375-385. https:// doi.org/10.1039/C6RP00186F

King, D. (2012). New perspectives on context-based chemistry education: using a dialectical sociocultural approach to view teaching and learning. Studies in Science Education, 48(1), 51-87. https:/ / doi.org/10.1080/03057267.2012.655037

Liu, C. K., \& Chiu, M. -H. (2012). Review and prospect of the development of our secondary school science curriculum over the past century. Science Education Monthly, 347, 2-20.

Liu, H. X. (2010). Centennial changes of basic education in Taiwan. Education and Examination, 2010(6), 88-93. https://doi.org/10.16391/j.cnki.jyks.2010.06.007

Liu, X., Liang, L. L., \& Liu, E. (2012). Science education research in China: challenges and promises. International Journal of Science Education, 34(13), 1661-1670. https:/ / doi.org/10.1080/09500693.2012.709330

MICSS. (1996). Upper secondary school chemistry (1st ed.), Malaysia: United Chinese School Committees' Association of Malaysia (Dong Zong).

Roberts, D. A. (1982). Developing the concept of "curriculum emphases" in science education. Science Education, 66(2), 243-260. https:/ / doi.org/10.1002/sce.3730660209

Roseman, J. E., Stern, L., \& Koppal, M. (2010). A method for analyzing the coherence of high school biology textbooks. Journal of Research in Science Teaching, 47(1), 47-70. https:/ / doi.org/10.1002/tea.20305

Seligardi, R. (2006). Views of chemistry and chemical theories: A comparison between two university textbooks in the Bolognese context at the beginning of the 19th century. Science $\mathcal{E}$ Education, 15, 713-737. https://doi.org/10.1007/s11191-005-2486-6

Shehab, S. S., \& BouJaoude, S. (2017). Analysis of the chemical representations in secondary Lebanese chemistry textbooks. International Journal of Science and Mathematics Education, 15(5), 797-816. https:/ / doi.org/10.1007/s10763-016-9720-3

Sjöström, J., Rauch, F., \& Eilks, I. (2015). Chemistry education for sustainability. In I. Eilks \& A. Hofstein (Eds.), Relevant chemistry education (pp. 163-184). Rotterdam: Sense. https:/ / doi.org/10.1007/978-94-6300-175-5_9

Song, X. Q. (Ed.). (2007a). Chemistry 1 (3rd ed.). Beijing: People Education Press.

Song, X. Q. (Ed.). (2007b). Chemistry 2 (3rd ed.). Beijing: People Education Press. 
Stein, M., Stuen, C., Carnine, D., \& Long, R. M. (2001). Textbook evaluation and adoption. Reading E Writing Quarterly, 17(1), 5-23. https:/ / doi.org/10.1080/105735601455710

Stuckey, M., Hofstein, A., Mamlok-Naaman, R., \& Eilks, I. (2013). The meaning of 'relevance' in science education and its implications for the science curriculum. Studies in Science Education, 49(1), 1-34. https:// doi.org/10.1080/03057267.2013.802463

Sun, Y. Q., Xu, D. F., Zhang, F. S., \& Zhao, C. X. (Eds.). (2016). 25 Years of Shanghai curriculum reform, Shanghai: Shanghai Educational Publishing House.

Talanquer, V. (2011). Macro, submicro, and symbolic: the many faces of the chemistry "triplet", International Journal of Science Education, 33(2), 179-195. https:/ / doi.org/10.1080/09500690903386435

Teddlie, C. \& Tashakkori, A. (Eds.). (2009). Foundations of mixed methods research: Integrating quantitative and qualitative approaches in the social and behavioral sciences. Thousand Oaks: Sage.

Van Berkel, B. (2005). The structure of current school chemistry - a quest for conditions for escape. Utrecht: CD- $\beta$.

Van Driel, J. H., Bulte, A. M. W., \& Verloop, N. (2007). The relationship between teachers' general beliefs about teaching and learning and their domain specific curricular beliefs. Learning and Instruction, 17(2), 156-171. https:/ / doi.org/10.1016/j.learninstruc.2007.01.010

Wang, L. (Ed.). (2007a). Chemistry 1 (3rd ed.). Shandong: Shandong Science and Technology Press.

Wang, L. (Ed.). (2007b). Chemistry 2 (3rd ed.). Shandong: Shandong Science and Technology Press.

Wang, L. (2010). Basic chemistry education curriculum reform progress and reflection in the past years (Volume I). Chinese Journal of Chemical Education, 31(4), 15-21.

Wang, L., Zhu, Y. J., Jiang, Y. X., Wei, R., Zhou, Y., Guo, Y. Y., Wei, X., Yang, W. Y., \& Liu E. S. (2016). Science education research in mainland China. In M.-H. Chiu (Ed.). Science education research and practice in Asia (pp. 17-39). Dordrecht: Springer. https://doi.org/10.1007/978-981-10-0847-4_2

Wang, S. H., \& He, C. X. (2012). The comparison of "chemical reaction rate" content represented in different high school chemistry textbooks. Teaching and Learning Reference for Middle School Chemistry, 2012(4), 40-43.

Wang, Z. H. (Ed.). (2014). Chemistry 1 (6th ed.). Nanjing: Jiangsu Education Press.

Wang, Z. H. (Ed.). (2015). Chemistry 2 (6th ed.). Nanjing: Jiangsu Education Press.

Wang, W. J., Wang J. Y., Zhang G. Z., Lang Y., \& Mayer V. J. (1996). Science education in the People's Republic of China. Science Education, 80(2), 202-223. https:/ / doi.org/10.1002/(SICI)1098-237X(199604)80:2<203::AIDSCE5>3.0.CO;2-K

Xiong, Z. D., \& Chen, J. C. (2001). A brief history of the evolution of science education in primary and secondary schools in Taiwan. Asia-Pacific Forum on Science Learning and Teaching, 2(1), 1-6.

Yao, Z. P. (Ed.). (2007a). Chemistry Volume 1 (1st ed.). Shanghai: Shanghai Scientific and Technical Publishers.

Yao, Z. P. (Ed.). (2007b). Chemistry Volume 2 (1st ed.). Shanghai: Shanghai Scientific and Technical Publishers.

Yeh, M. C. P. (Ed.). (2010). Basic Chemistry 1 (1st ed.). Taiwan: Nan I Book Enterprise Co., Ltd.

Zhong, X. M. (2005). Challenge and development. Curriculum, Teaching Material and Method, 25(8), 79-83. 


\section{APPENDIX 1}

\section{Overview about the Textbooks}

\begin{tabular}{|c|c|c|c|c|c|c|}
\hline Country & Chief Editor & Title & Publisher & Version & $\begin{array}{c}\text { Publication } \\
\text { Date }\end{array}$ & Edition \\
\hline \multirow{8}{*}{$\begin{array}{l}\text { People's } \\
\text { Republic of } \\
\text { China }\end{array}$} & Xinqi Song & Chemistry 1 & PEP & $\begin{array}{l}\text { Renjiao } \\
\text { Edition }\end{array}$ & March 2007 & $3 r d$ \\
\hline & Xinqi Song & Chemistry 2 & PEP & $\begin{array}{l}\text { Renjiao } \\
\text { Edition }\end{array}$ & March 2007 & $3 r d$ \\
\hline & Zuhao Wang & Chemistry 1 & JEP & $\begin{array}{c}\text { Sujiao } \\
\text { Edition }\end{array}$ & June 2014 & 6th \\
\hline & Zuhao Wang & Chemistry 2 & JEP & $\begin{array}{l}\text { Sujiao } \\
\text { Edition }\end{array}$ & June 2015 & 6th \\
\hline & Lei Wang & Chemistry 1 & SSTP1 & $\begin{array}{c}\text { Luke } \\
\text { Edition }\end{array}$ & July 2007 & $3 r d$ \\
\hline & Lei Wang & Chemistry 2 & SSTP1 & $\begin{array}{c}\text { Luke } \\
\text { Edition }\end{array}$ & July 2007 & $3 r d$ \\
\hline & Zipeng Yao & Chemistry & SSTP2 & $\begin{array}{l}\text { Shangke } \\
\text { Edition }\end{array}$ & July 2007 & 1 st \\
\hline & Zipeng Yao & Chemistry & SSTP2 & $\begin{array}{l}\text { Shangke } \\
\text { Edition }\end{array}$ & January 2007 & $1 \mathrm{st}$ \\
\hline \multirow{2}{*}{ Taiwan } & Ded-Shih Huang & $\begin{array}{c}\text { Basic Chemistry } \\
1\end{array}$ & LTC & $\begin{array}{l}\text { Lungteng } \\
\text { Edition }\end{array}$ & March 2010 & $1 \mathrm{st}$ \\
\hline & $\begin{array}{c}\text { Ming-Chang P. } \\
\text { Yeh }\end{array}$ & $\begin{array}{c}\text { Basic Chemsitry } \\
1 \\
\end{array}$ & Nan I & $\begin{array}{c}\text { Nan I } \\
\text { Edition }\end{array}$ & April 2010 & $1 \mathrm{st}$ \\
\hline Malaysia & MICSS & $\begin{array}{c}\text { Upper } \\
\text { Secondary } \\
\text { School } \\
\text { Chemistry }\end{array}$ & Dong Zong & Malaysia & November 1996 & $1 \mathrm{st}$ \\
\hline
\end{tabular}

Note. PEP=People's Education Press, JEP=Jiangsu Education Press, SSTP1=Shandong Science and Technology Press, SSTP2=Shanghai Scientific and Technical Publishers, LTC=LungTeng Culture Lungteng Cultural Co., Ltd, Nan I= Nan I Book Enterprise Co., Ltd, Dong Zong=United Chinese School Committees' Association of Malaysia. 


\section{APPENDIX 2}

\section{Main Topics of the Curriculum Referring to the Textbooks}

\begin{tabular}{|c|c|}
\hline Textbook & topic \\
\hline CN1 & $\begin{array}{l}\text { - chemistry from the experiment } \\
\text { - chemical substances } \\
\text { - } \text { non-/metals and their compounds } \\
\text { - chemical reactions and energy } \\
\text { - chemic compounds } \\
\text { - chemistry and natural resources }\end{array}$ \\
\hline $\mathrm{CN} 2$ & $\begin{array}{l}\text { - } \quad \text { chemical sciences } \\
\text { - } 3 \text { chapters related to elements } \\
\text { - } \quad \text { atomic structure and the periodic table } \\
\text { chemical bond, chemical reaction and energy } \\
\text { - } \quad \text { organic compounds }\end{array}$ \\
\hline $\mathrm{CN} 3$ & $\begin{array}{l}\text { - } \quad \text { the material world } \\
\text { - } \quad \text { mineawater resources } \\
\text { - } \quad \text { sulphur, nitrogen and sustainable development } \\
\text { - } \text { macrostructure and material diversity } \\
\text { chemical reaction and energy } \\
\text { - } \quad \text { cheminic compounds } \\
\end{array}$ \\
\hline CN4 & 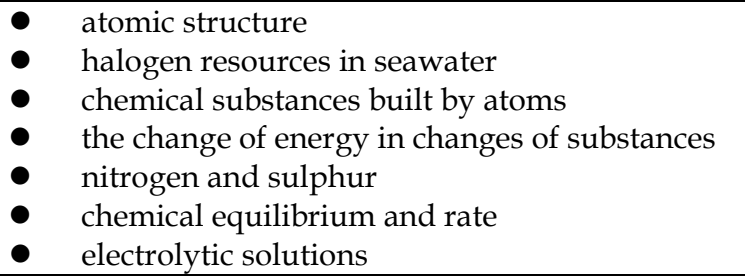 \\
\hline TW1 & $\begin{array}{ll}\text { - } & \text { composition and properties of matter } \\
\text { - } & \text { atomic structure and periodic table } \\
\text { - } & \text { chemical reactions } \\
\text { - } & \text { chemistry and energy }\end{array}$ \\
\hline TW2 & $\begin{array}{ll}\text { - } & \text { composition of matter } \\
\text { - } & \text { atomic structure and periodic table } \\
\text { - } & \text { chemical equations and chemical calculation } \\
\text { - chemistry and energy }\end{array}$ \\
\hline MY1 & $\begin{array}{ll}\text { - } & \text { introduction } \\
\text { - } & \text { water and hydrogen } \\
\text { - } & \text { chemical equations and calculations } \\
\text { - } & \text { atomic structure } \\
\text { - } & \text { periodic table } \\
\text { - } & \text { redomical bonds } \\
\text { - } & \text { halogens } \\
\text { - } & 2 \text { chapters of metals and their compounds } \\
\text { - } & 3 \text { chapters of non-metals and their compounds }\end{array}$ \\
\hline
\end{tabular}




\section{APPENDIX 3}

Selected Findings from the First Round of Analysis

\begin{tabular}{|c|c|c|c|c|c|c|c|}
\hline \multirow{2}{*}{ Criteria } & \multicolumn{4}{|c|}{ People's Republic of China } & \multicolumn{2}{|c|}{ Taiwan } & \multirow{2}{*}{$\begin{array}{c}\text { Malaysia } \\
\text { MY1 }\end{array}$} \\
\hline & CN1 & $\mathrm{CN} 2$ & CN3 & CN4 & TW1 & TW2 & \\
\hline Pages & 223 & 242 & 220 & 185 & 189 & 180 & 347 \\
\hline Chapters & 8 & 7 & 8 & 7 & 4 & 4 & 14 \\
\hline Pictures & 155 & 277 & 161 & 138 & 148 & 106 & 201 \\
\hline $\begin{array}{l}\text { Pictures from everyday } \\
\text { life }\end{array}$ & 59 & 124 & 61 & 33 & 62 & 34 & 65 \\
\hline $\begin{array}{l}\text { Pictures with human } \\
\text { beings }\end{array}$ & 4 & 5 & 3 & 2 & 4 & 2 & 7 \\
\hline $\begin{array}{l}\text { Pictures using the sub- } \\
\text { microscopic level }\end{array}$ & 13 & 31 & 29 & 15 & 17 & 19 & 16 \\
\hline $\begin{array}{l}\text { References to modern } \\
\text { challenges related to } \\
\text { chemistry, e.g. } \\
\text { sustainability issues or } \\
\text { modern technologies }\end{array}$ & 13 & 11 & 15 & 7 & 25 & 14 & 5 \\
\hline $\begin{array}{c}\text { Reference to } \\
\text { experiments (simple } \\
\text { experiments, inquiry } \\
\text { experiments, } \\
\text { demonstrations) } \\
\end{array}$ & 52 & 71 & 44 & 62 & 17 & 20 & 40 \\
\hline $\begin{array}{l}\text { Practical activities (e.g. } \\
\text { building molecular } \\
\text { structures, site visits, } \\
\text { pH test of rainwater, } \\
\text { etc.) }\end{array}$ & 9 & 5 & 2 & 3 & 2 & 1 & 0 \\
\hline
\end{tabular}

\section{http://www.ejmste.com}

